\title{
Comportamento do Consumidor de Produtos de Acabamentos
}

Consumer Behavior of Furnishings Products

Gabriele Back Carvalho - gabriele.back@hotmail.com

MirelaJeffman dos Santos - mirelajs@unisc.br

\section{RESUMO}

No cenário dinâmico e competitivo, no qual as empresas disputam a preferência do cliente, analisar o comportamento do consumidor tornou-se uma necessidade para sobrevivência dos negócios. O setor de construção civil, especialmente, tem sofrido os efeitos diretos da crise econômica do país nos últimos anos, o que impacta diretamente no mercado de produtos de reforma e acabamentos. O objetivo deste estudo foi analisar 0 comportamento do consumidor de produtos de acabamentos. $\bigcirc$ aporte teórico do estudo englobou comportamento do consumidor, especificamente o processo de decisão de compra e a satisfação. A pesquisa de campo de natureza quantitativa abrangeu uma amostra de 50 consumidores de produtos de acabamentos. Os resultados indicaram que os consumidores costumam buscar informações no mercado antes de realizar a compra de acabamentos e avaliam de forma criteriosa as ofertas disponíveis. A decisão de compra é tomada, principalmente, com base nos atributos de qualidade, preço, variedade de marcas, condições de pagamentos e atendimento. De um modo geral, os consumidores se revelaram satisfeitos com as suas compras e com o fornecedor escolhido, especialmente no que se refere à estrutura física da loja, à variedade de produtos e marcas encontrados e ao atendimento recebido no ato da compra. Por fim, foram apresentadas contribuições, limitações e sugestões para novos estudos na área.

Palavras-chave: Comportamento do Consumidor; Satisfação; Setor de acabamentos. 


\section{ABSTRACT}

In dynamic and competitive scenario in which companies compete for customer preference, analyzing consumer behavior has become a necessity for business survival. The civil construction sector, in particular, has suffered the direct effects of the country's economic crisis in recent years, which has a direct impact on the market for renovation and finishing products. This study objective was to analyze the consumer behavior of furnishings products. The theoretical background of the study encompassed consumer behavior, especially the purchasing decision process and satisfaction. The quantitative field research covered a survey with a sample of 50 customers of finishing products.The results indicated that consumers often seek information in the marketplace prior to the purchase of finishes and carefully evaluate available offers. The purchase decision is made, mainly, based on the attributes of quality, price, brand variety, payment terms and attendance. In general, consumers have been satisfied with their purchases and with the chosen supplier, especially with regard to the physical structure of the store, the variety of products and brands found and the attendance received at the time of purchase. Finally, contributions, limitations and suggestions for new studies in the area were presented.

Keywords: Consumer Behavior; Satisfaction; Sector of finishes.

\section{INTRODUÇÃO}

Os avanços na tecnologia, as inovações e o surgimento de novos produtos no mercado fizeram com que o consumidor passasse a ter mais vontade de consumir e se tornasse mais exigente, especialmente com a difusão da internet que proporcionou o amplo acesso à informação facilitando a comparação entre ofertas, marcas, produtos e serviços. Desta forma, quando o indivíduo se percebe com alguma necessidade, recorre a ferramentas online fazendo uma pesquisa para ter noção de opções de produtos, além de fotos, do funcionamento e dos benefícios que o bem em questão pode lhe proporcionar (Paladino, 2008). 
O mercado está cada vez mais competitivo, e para obter sucesso nos negócios, é fundamental inovar e buscar produtos que satisfaçam as necessidades dos consumidores (Reid\& Brentani, 2010). Diante disso, conhecer profundamente o consumidor é essencial para que as organizações identifiquem as suas necessidades e possam desenvolver produtos e diferenciais que criem valor no mercado (Ingenbleek, Frambach\&Verhallen, 2010; Paixão, 2012). O estudo do comportamento do consumidor possibilita a identificação de necessidades desatendidas no mercado, proporcionando condições para que as empresas direcionem suas estratégias para responder a essas demandas e atender de forma mais plena as preferências dos consumidores (WU, 2013; Basso \&Espartel, 2015).

O setor de construção civil, especialmente, tem sofrido os efeitos diretos da crise econômica do país nos últimos anos, o que impacta diretamente no mercado de produtos de reforma e acabamentos. Esse cenário torna ainda mais desafiador a compreensão do comportamento desse consumidor, que se apresenta mais exigente e cauteloso para tomar a sua decisão de compra. O presente estudo teve por objetivo analisar o comportamento do consumidor de produtos de acabamentos, especificamente louças, metais, porcelanatos e revestimentos. Para isso, o estudo focou-se em identificar as necessidades e desejos dos consumidores, analisar como ocorre o processo de decisão de compra e avaliar o seu grau de satisfação pós-compra.

O artigo está dividido em cinco partes, incluída esta introdução. A seguir, apresenta-se o referencial teórico do tema de estudo. Na sequência, descreve-se o método utilizado na pesquisa de campo. Após, os resultados são apresentados e analisados. Por fim, contribuições, limitações e sugestões são expostas nas considerações finais.

\section{REFERENCIALTEÓRICO}

Marketing \&amp; Tourism Review • Belo Horizonte - MG - Brasil • v. 4, n. 2, ago-dez, 2019 
Nesta seção apresentam-se os temas comportamento do consumidor, necessidades, processo de decisão de compra e satisfação.

\section{Comportamento do Consumidor}

O comportamento do consumidor pode ser entendido como o estudo dos processos de como e quando indivíduos ou grupos selecionam, compram e usam produtos, serviços, ideias e experiências para satisfazerem suas necessidades e desejos (Solomon, 2016). O ato de consumir se constitui em uma experiência complexa, que extrapola aspectos racionais e práticos e envolve também sentimentos e emoções por parte do consumidor (Holt, 1995).

Os bens de consumo não são adquiridos exclusivamente pela sua característica utilitária: eles têm o poder de carregar e comunicar significados (McCracken, 1986). As pessoas têm a tendência de fazer inferências sobre as outras baseadas nos objetos que elas escolhem consumir. Por isso, os consumidores preferem produtos cujas imagens são similares às imagens que eles têm deles mesmos (Belk, Bahn\& Mayer, 1982) ou que gostariam de ter (Merskin, 2007). Assim, o indivíduo pode estabelecer um forte laço de afeto com o bem que está consumindo (Belk, Ger\&Askegaard, 2003).

O consumo é uma forma não verbal de demonstração da personalidade do indivíduo, além de ser considerado um fenômeno social capaz de proporcionar experiência e diversão ao consumidor (Holt, 1995). Por isso, torna-se tão complexo e deve ser cuidadosamente estudado pelas organizações que almejam se destacar no mercado.

Decisões de compra são tomadas a todo o momento, em diversos lugares e por vários indivíduos. Compreender o que leva o consumidor a decidir por determinado produto, suas motivações e desejos, bem como analisar como as pessoas buscam, escolhem, adquirem, utilizam e descartam produtos é fundamental para o sucesso de qualquer negócio (Ribeiro, 2015). 


\section{Necessidades do consumidor}

As necessidades podem ser definidas como carências humanas, físicas ou psicológicas, que se tornam latentes em determinado momento, e que podem impulsionar a aquisição de produtos (Solomon, 2016).Ao longo da história, as necessidades humanas foram estudadas principalmente pela área da Psicologia e assumiram diversas definições na literatura (Brei, 2007). As necessidades humanas podem ser divididas em fisiológicas, de segurança, sociais, de autoestima e de autorrealização. Diferentes produtos podem atender à mesma necessidade de uma pessoa e o mesmo produto pode atender diferentes necessidades. Fazendo um estudo para conhecer melhor as necessidades do consumidor, as organizações se tornam aptas a criar produtos que atendam às necessidades de forma plena e duradoura (Reichelt, 2013).

Segundo a teria de Maslow, as pessoas são motivadas a agir por necessidades não atendidas. Nesta linha, os indivíduos satisfazem certas necessidades básicas, para após, sentirem-se altamente motivados a saciar as outras. O autor propôs uma hierarquia de cinco níveis de necessidades, de acordo com o que as pessoas buscam e necessitam para sentirem-se satisfeitas, que indica que as necessidades devem ser razoavelmente satisfeitas antes que a pessoa resolva ir para o próximo nível da pirâmide (Ełzel, Walker \&Stanton, 2001). A hierarquia das necessidades de Maslow coloca muitas vezes em pauta a real necessidade humana. A pirâmide criada pelo autor justifica como e porque o consumidor está cada vez mais exigente, questionando novas estruturas sociais e mercadológicas existentes, uma vez que suas necessidades básicas já estão supridas (Ferreira Junior \&Centa, 2014).

As necessidades podem ser classificas também em utilitárias e hedônicas. As utilitárias relacionam-se a funções básicas e benefícios materiais. Quando as pessoas são motivadas a satisfazerem esse tipo de necessidade, elas tendem a ser racionais em suas escolhas. As necessidades 
hedônicas estão relacionadas ao desejo de prazer e auto expressão e tendem a ser relativamente emocionais (Gasper, 1996).

\section{Processo de decisão de compra do consumidor}

Em um processo de decisão de compra, existem cinco papéis que podem ser desempenhados por uma pessoa, sendo eles: o iniciador, que se refere a um indivíduo que sugere a ideia de comprar algo;0 influenciador que influencia na decisão de acordo com seu ponto de vista; o decisor, que é quem decide o que, como, quando e onde comprar; o comprador, que efetivamente realiza a compra e o usuário, que é quem consome ou usa o produto (Brandão, 2005).

Para fazer suas compras, os consumidores envolvem-se em um processo de decisão. Essa decisão pode ser encarada como um problema, que se manifesta quando o consumidor percebe que algo está faltando e consequentemente resolve procurar uma solução para sentir-se satisfeito. Nesse processo de compra, os clientes passam por uma série de estágios lógicos para escolher o produto mais adequado: reconhecimento da necessidade, busca por informações, avaliação das alternativas, decisão de compra e comportamento pós-compra (Ełzelet al., 2001).

A identificação da necessidade é resultado da discrepância entre o estado atual e o estado desejado, de modo suficiente para despertar e ativar o processo de decisão (Hawkins\&Mothersbaugh, 2019). Essa identificação pode acontecer de diversas formas, sendo que as principais são quando ele identifica a necessidade de obter um novo produto ou está insatisfeito com o produto atual. Quanto maior for a diferença entre o estado desejado em relação ao estado real, mais motivado o consumidor ficará para iniciar o processo de tomada de decisão (Nickles\& Wood, 1999).

Embora o reconhecimento de um problema aconteça de maneira natural, o processo também pode ser acionado por influências externas, como por exemplo, os profissionais de marketing que estimulam o 
consumidor a experimentar produtos que ainda não são conhecidos por ele, com o intuito de incentivar a compra (Solomon, 2016).

Uma vez reconhecida a necessidade, o consumidor parte para a busca de informações. Inicialmente, o indivíduo considera a sua memória de experiências passadas, pesquisas anteriores e aprendizados, engajando-se assim num processo de busca interna (Hawkins\&Mothersbaugh, 2019). Caso mais informações sejam necessárias, o consumidor inicia uma busca externa, procurando outras fontes, como opiniões de familiares ou conhecidos ou pesquisas de mercado (Nickles\& Wood, 1999).As informações externas podem se originar de diversas fontes. As principais são: as fontes de marketing (como propagandas, vendedores, folhetos e internet), as fontes pessoais (indivíduos do convívio social), fontes independentes (como análises de produtos feitos por órgãos de defesa do consumidor) e experimentais (testar o produto para viver momentaneamente a experiência de possui-lo) (Crocco, Thelles, Gioia, Rocha \&Strehlau, 2013; Hawkins\&Mothersbaugh, 2019).

Após coletar as informações necessárias, o indivíduo passa para a etapa de analisar as alternativas disponíveis. Nesse estágio, o consumidor avalia os atributos que considera importantes no produto ou serviço, descarta as opções que não atendem a esses critérios e limita o seu conjunto de alternativas. Para o novo conjunto considerado, o consumidor realiza uma ponderação dos atributos de cada opção com o intuito de identificar a melhor alternativa existente (Solomon, 2016).

Depois de examinar as alternativas, o cliente necessita fazer três escolhas: o que comprar, quando comprar e como pagar. A decisão de quando comprar é determinada por vários fatores. Se o produto estiver na promoção ou com um desconto especial, o cliente pode se motivar e efetuar logo a compra, caso contrário se sua necessidade não for imediata, ele pode aguardar o momento mais oportuno. Ou então, se a empresa oferecer condições de pagamento parcelado, fazendo com que o cliente entenda que fará um bom negócio optando por aquela forma de 
pagamento que Ihe foi proposta, poderá adquirir o produto (Pinheiro, Castro, Silva \& Nunes, 2006).

O consumidor pode desistir da compra também por motivos como: não encontrar a marca ou produto que realmente Ihe satisfaça, por uma modificação na sua necessidade, que pode ter sido atendida de outra forma, ou então pelo fato de ter surgido uma nova informação que faça com que a avaliação até então tomada não seja satisfatória (Croccoet al. 2013).

Por fim, o consumidor passa para o estágio de avaliação pós-compra. Durante esse estágio, ele avalia se o produto adquirido e a experiência de compra atendem suas expectativas, gerando a sua satisfação ou insatisfação. A satisfação também pode fazer com que o cliente quando sentir novamente uma necessidade se lembre do produto anteriormente comprado na empresa e resolva repetir a sua compra (Nickles\& Wood, 1999).

O processo pós-compra inclui quatro etapas: confirmação da decisão, avaliação da experiência, satisfação ou insatisfação e resposta futura. Logo após a compra, o cliente utiliza o produto e define se fez ou não uma boa escolha ao comprá-lo, avaliando essa experiência (Hawkins\&Mothersbaugh, 2019). Se a utilização do produto for eficaz, o cliente se sentirá satisfeito, caso contrário, insatisfeito. Isso incidirá numa resposta futura, se ele retornará a comprar o produto ou desconsiderará essa ideia, pelo fato de o produto não ter atingido suas expectativas (Czinkota, 2001).

\section{Satisfação do consumidor}

A satisfação do consumidor pode ser compreendida como a avaliação da lacuna entre a expectativa e o desempenho do produto ou serviço. O consumidor considera-se satisfeito se o desempenho por ele experimentado atende ou excede a expectativa (Strehl, Mello Moyano\&Angnes, 2019). Portanto, a satisfação do consumidor depende do desempenho do produto ou serviço em comparação às suas expectativas, 
que podem ser positivas ou negativas. Se o desempenho alcançar as expectativas, o indivíduo ficará satisfeito, caso contrário, gerará insatisfação (Zeithaml, Bitner\&Gremler, 2014).

Para avaliar a satisfação, é importante identificar os benefícios que o consumidor espera dobem que está adquirindo. $\bigcirc$ valor percebido se refere ao conjunto de benefícios esperados com a compra - sendo formado de acordo com experiências passadas em outros momentos ou por recomendações de pessoas conhecidas - em detrimento dos custos que o consumidor precisa despender para efetuar a compra (Cobra, 2009; Hawkins\&Mothersbaugh, 2019).

As expectativas dos clientes podem ser provenientes de diversas fontes, como: a comunicação da empresa no mercado, que se refere à divulgação para atrair o consumidor, criando expectativas em relação aos benefícios do produto - a propaganda boca a boca, que consiste na comunicação entre consumidores para propagar informações sobre produtos e serviços, podendo gerar tanto recomendações positivas quanto negativas - e as necessidades individuais, que compreendem a motivação, a percepção e as impressões que o consumidor possui sobre o bem que está considerando comprar (Reichelt, 2013; Solomon, 2016).

As empresas que detêm altos níveis de satisfação do consumidor têm maior capacidade para diferenciar-se e conquistar posições destacadas no mercado. Os consumidores satisfeitos tornam-se dispostos a pagar mais pelo produto, pois já confiam nos benefícios que este proporciona (Czinkota, 2001), além de apresentarem probabilidades mais altas para efetuar recompras (Hawkins\&Mothersbaugh, 2019).

Deste modo, a satisfação se trata deuma resposta afetiva do consumidor diante das suas expectativas e percepções (Strehl, Mello Moyano\&Angnes, 2019), ou seja, está relacionada ao sentimento que o consumidor possui quando considera as suas expectativas atendidas com determinado bem de consumo (Reichelt, 2013). 


\section{MÉTODO}

O presente estudo teve por objetivo analisar o comportamento do consumidor de produtos de acabamentos. A pesquisa de campo envolveu abordagem direta aos consumidores, buscando identificar suas necessidades e desejos, analisar como ocorre o seu processo de decisão de compra e avaliar o seu grau de satisfação.

A pesquisa realizada foi de natureza quantitativa descritiva, pois o propósito deste trabalho foi obter uma maior abrangência dos fatores que os consumidores levam em consideração em sua decisão de compra, além de suas necessidades e satisfação. Segundo Mascarenhas (2012), a pesquisa quantitativa baseia-se na quantificação para coletar e tratar os dados obtidos, por meio de técnicas estatísticas como porcentagens e médias, para tornar o estudo mais imparcial.

A amostra da pesquisa foi constituída pelo critério de conveniência, seguindo as recomendações de Malhotra (2001),por meio do aceite dos consumidores em participar da pesquisa durante o período de coleta de dados, que se deu nos meses de agosto e setembro de 2017 e abrangeu 50 consumidores de produtos de acabamentos.

A pesquisa foi conduzida através de um survey, no qual os clientes foram abordados pessoalmente no ponto de venda. O método survey se baseia em questionamentos feitos aos participantes, aos quais se fazem várias perguntas sobre seus comportamentos, intenções, atitudes, motivações e percepções e de estilo de vida (Malhotra, 2001). Neste estudo, o survey foi conduzido na loja física de uma empresa de acabamentos localizada no estado do Rio Grande do Sul.

O instrumento utilizado para coleta de dados desta pesquisa foi 0 questionário. Conforme as orientações de Malhotra (2001), o questionário contou com questões fechadas de escolha múltipla e também com escalas do tipo Likert (de concordância e de satisfação) para maior facilidade na obtenção de informações. O instrumento apresentou perguntas sobre o perfil dos respondentes como sexo, idade, renda e estado civil, bem como 
questões relacionadas ao comportamento de compra na loja de acabamentos, como fonte de busca de informações, frequência de compra e possibilidade de compra virtual, cujas opções de resposta foram apresentadas em formato de múltipla escolha.

As questões referentes ao processo de decisão de compra foram apresentadas em forma de afirmativas com escala Likert de cinco pontos, que retrataram graus de concordância. As afirmativas foram construídas com base na literatura, especificamente no processo de decisão de compra (Solomon, 2016; Etzelet al., 2001).

As questões referentes à satisfação apresentaram indicadores para os quais os respondentes deveriam assinalar o seu grau de satisfação em escala Likert de cinco pontos. Esses indicadores foram embasados na literatura de marketing focada em satisfação de clientes (Etzelet al. (2001; Crocco et al. 2013; Solomon, 2016).

No Quadro 1 apresentam-se os indicadores de satisfação avaliados neste estudo e as afirmativas consideradas para análise do processo de decisão de compra.

\section{Quadro 1: Itens avaliados no instrumento de pesquisa}

\begin{tabular}{|c|c|}
\hline \multirow{4}{*}{$\begin{array}{l}\text { o } \\
\text { ํㅡㄹ } \\
\text { ல }\end{array}$} & Quando reconheço uma necessidade de acabamentos, sempre vou a esta loja. \\
\hline & Eu busco informações sobre os benefícios do produto na internet. \\
\hline & Eu analiso várias marcas quando busco informações dos acabamentos. \\
\hline & $\begin{array}{l}\text { Eu costumo pedir opinião de pessoas do meu convívio quando vou comprar } \\
\text { acabamentos. }\end{array}$ \\
\hline \multirow{9}{*}{ 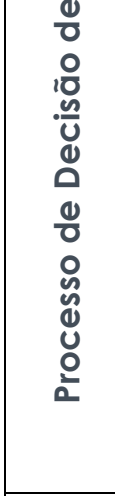 } & Sempre faço uma pesquisa de mercado antes de comprar acabamentos. \\
\hline & Eu considero a qualidade o fator principal para realizar a compra. \\
\hline & Eu considero o preço o fator principal para realizar uma compra. \\
\hline & Eu sempre analiso mais de um orçamento antes de realizar minha compra. \\
\hline & Para realizar uma compra, os produtos necessitam ser entregues no mesmo dia. \\
\hline & O atendimento é essencial na decisão da minha compra. \\
\hline & Eu levo muito em consideração a forma de pagamento. \\
\hline & Eu não abro mão de comprar produtos classe A. \\
\hline & $\begin{array}{l}\text { Eu considero importante um projetista à disposição para melhor visualizar o meu } \\
\text { projeto. }\end{array}$ \\
\hline \multirow{6}{*}{ 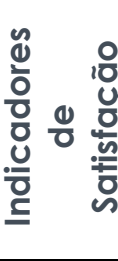 } & Qualidade dos produtos \\
\hline & Variedades em opções \\
\hline & Marcas oferecidas \\
\hline & Quantidade de produtos a pronta entrega \\
\hline & Prazo de entrega \\
\hline & Horário de atendimento \\
\hline
\end{tabular}




\begin{tabular}{|l|l|}
\hline Cafezinho oferecido \\
\hline Formas de pagamentos oferecidas \\
\hline Localização da loja \\
\hline Estacionamento \\
\hline Estrutura e layout da loja \\
\hline Iluminação e limpeza \\
\hline Atendimento pelo telefone \\
\hline Informações passadas pelos vendedores \\
\hline Ofertas oferecidas \\
\hline Divulgação dos produtos através de redes sociais \\
\hline Atendimento no pós-venda \\
\hline
\end{tabular}

Fonte: dados da pesquisa

Os dados coletados na pesquisa foram tabulados na ferramenta Excel, no qual procederam-se os cálculos da estatística descritiva, com frequência, percentual, média e desvio padrão. Os resultados foram apresentados em formato de tabelas e gráficos, seguindo os critérios de Malhotra (2001).

\section{APRESENTAÇÃO DOS RESULTADOS}

Por meio da pesquisa realizada na empresa, identificou-se que dos 50 consumidores participantes, $56 \%$ são do sexo feminino e $44 \%$ do sexo masculino. $32 \%$ estão faixa etária de 41 a 50 anos, $26 \%$ estão acima dos 50 anos, $26 \%$ entre 31 a 40 anos e $16 \%$ têm de 20 a 30 anos. A pesquisa também mostrou que $66 \%$ dos entrevistados são casados, enquanto que $24 \%$ são solteiros, $6 \%$ divorciados e $4 \%$ viúvos. $38 \%$ da amostra pesquisada possui a renda salarial de 4 a 5 salários mínimos, vindo logo em seguida a renda acima de 7 salários mínimos com 28\%. Após, com uma porcentagem parecida ficaram os de 6 a 7 salários mínimos com 18\%, e os de 2 a 3 salários mínimos com $16 \%$.

Esses dados demonstram que os consumidores de produtos de acabamentos pesquisados são tanto homens quanto mulheres. Possivelmente pelo fato da maioria ser casada e pelo fato de o casal querer que o ambiente de sua residência fique da maneira que os dois gostem. Percebeu-se também que a maioria possui idade acima dos 40 anos, tendo uma renda alta com grande potencial de compra. Esse perfil retrata o tipo de público consumidor de produtos de acabamentos, em geral, são pessoas 
maduras, com renda alta e casadas, sugerindo que este é o momento da vida em que há interesse por produtos deste tipo.

\section{Comportamento de Compra do Consumidores}

Com o intuito de analisar o processo de decisão de compra dos consumidores, o questionário apresentou questões referentes ao reconhecimento de uma nova necessidade de acabamentos, fontes de busca de informações sobre o produto, critérios de escolha do produto e a consideração da opinião de terceiros ao realizar uma compra (Solomon, 2016). A Figura 1 apresenta estes resultados no formato de gráfico.

Figura 1: Comportamento do Consumidor na Pré-compra

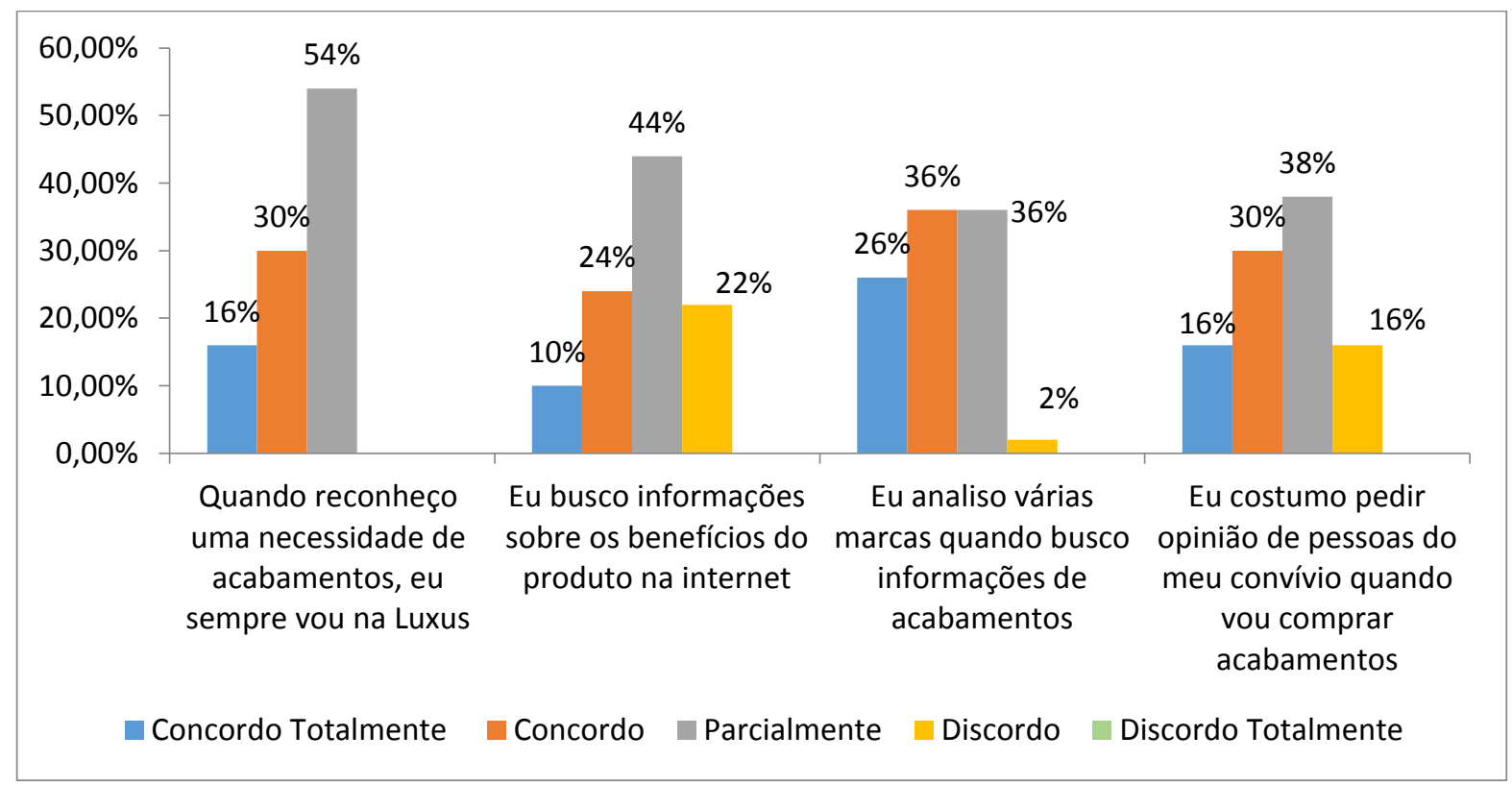

Fonte: dados da pesquisa

A pesquisa revelou que $30 \%$ dos participantes concordaram e $16 \%$ concordaram totalmente quando foi thes questionado se ao reconhecem uma necessidade, costumam procurar sempre a mesma loja, 54\% concordaram parcialmente, o que demonstrou que os respondentes tendem a associar diretamente uma empresa específica quando o assunto é materiais de acabamentos. 
Em relação ao comportamento de busca de informações sobre os benefícios dos produtos na internet, $10 \%$ concordaram totalmente que costumam fazer, $24 \%$ concordaram, $44 \%$ responderam que concordam parcialmente e $22 \%$ discordaram. Esses dados mostram que existem diferenças de comportamentos entre os consumidores quanto à busca por informações de produtos, pois alguns fazem a busca pela internet e outros não. Esse resultado retrata as colocações de Hawkins\&Mothersbaugh(2019), que identificam múltiplas fontes de informações para busca do consumidor.

Quando Ihes foi questionado se analisam várias marcas quando buscam informações sobre acabamentos, as respostas "concordo" e "parcialmente" foram as mais assinaladas com $36 \%$ cada, seguida dos que concordam totalmente com 26\%, indicando que os consumidores pesquisados analisam as marcas de acabamentos para ter a certeza de fazer uma compra certa, afinal os produtos de acabamentos normalmente só são trocados após um significativo período de tempo e envolve valores mais elevados de compra. Esse resultado reforça o que Etzelet al. (2001) e Solomon (2016)afirmam quanto ao envolvimento dos consumidores com a compra: produtos de acabamento se mostram uma compra de alto envolvimento.

Durante o processo de compra, nem todos costumam pedir opiniões para outras pessoas de seu convívio. O gráfico mostra que 38\% dos entrevistados responderam que concordam parcialmente nesta questão, e $16 \%$ que discordam, deixando claro assim, que eles preferem decidir por si próprio o que comprar. Já por outro lado, 30\% responderam que concordam com a afirmação e $16 \%$ que concordam totalmente, mostrando que preferem a opinião de uma pessoa de seu convívio para dar uma opinião e auxilia-lo na melhor escolha, reforçando a ideia de Nickles e Wood (1999) que comentam sobre os clientes pedirem opiniões antes de realizarem uma compra, principalmente os familiares. Nesta questão, novamente, percebese a divergência de comportamentos na amostra pesquisada, que se revelou dividida no que se refere às influências sociais. 
Em relação aos atributos considerados pelos clientes para tomar sua decisão de compra, conforme retratado na Figura 2, 52\% dos consumidores concordam e $34 \%$ concordam totalmente que a qualidade se trata do fator principal para realizar a compra. 52\% afirmaram não abrir mão de produtos classe A. Esses resultados retratam o perfil de consumidores pesquisados, que possuem alta renda, fazendo com que optem por produtos de alto padrão.

Figura 2: Atributos considerados pelo consumidor

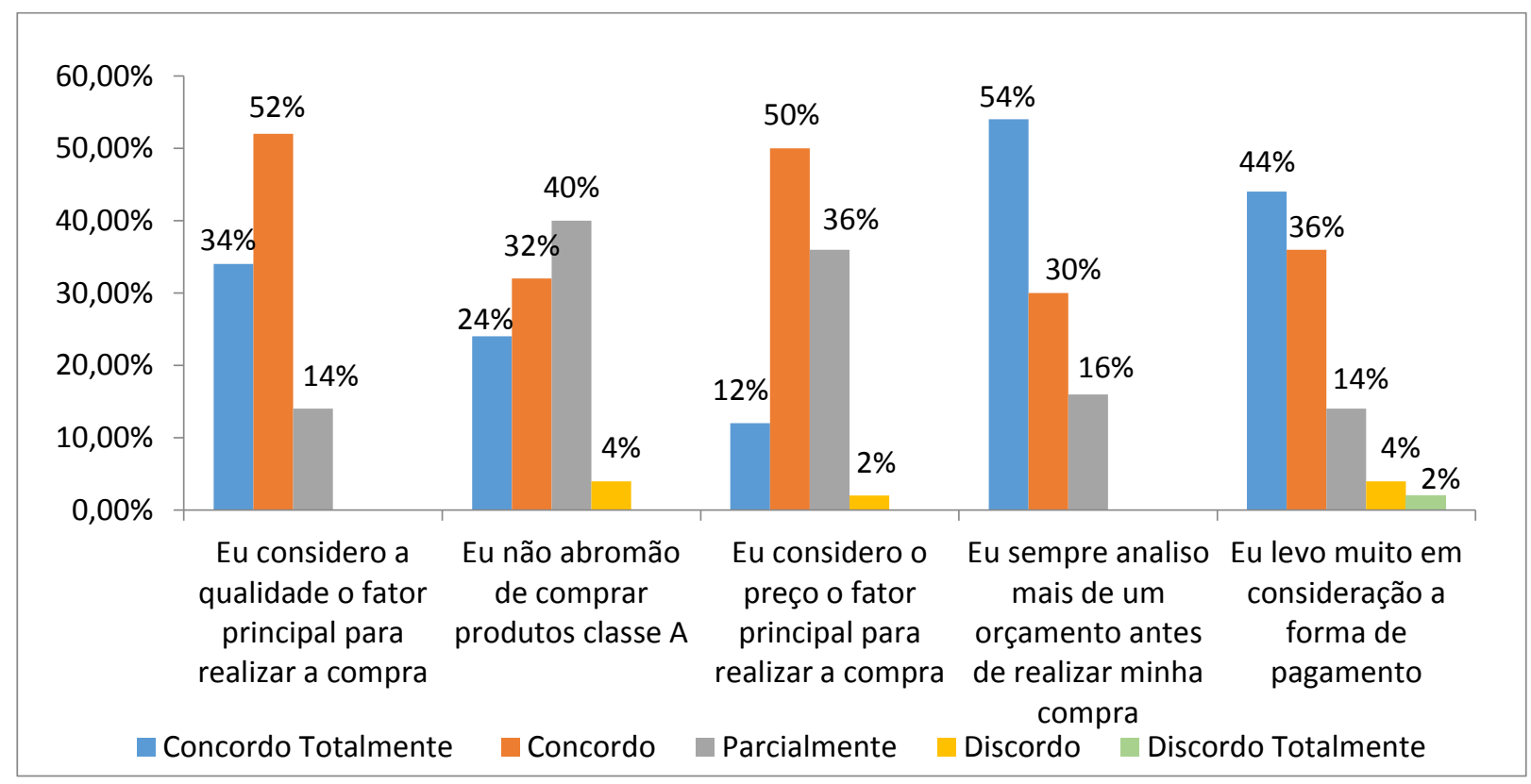

Fonte: dados da pesquisa

Já em relação ao preço, 62\% responderam que o consideram o fator principal para realizar a compra, enquanto $36 \%$ marcaram parcialmente e $2 \%$ discordaram. Essa questão mostrou que os consumidores que integraram a amostra de estudo procuram produtos com qualidade, mas com um preço que também Ihes satisfaça para que a compra seja concretizada. A preocupação com o preço dos produtos é reforçada na afirmativa referente à análise de orçamentos antes de realizar a compra. $84 \%$ dos participantes responderam que fazem esta análise, enquanto os outros $16 \%$ afirmaram fazer parcialmente. Esse resultado possivelmente está relacionado ao fato de os consumidores pesquisados analisarem a qualidade e marca do produto, para que identifiquem a opção de maior valor. Este 
comportamento também foi retratado na afirmativa referente à forma de pagamento, para a qual $36 \%$ concordaram com a questão e $44 \%$ concordaram totalmente, pois a forma de pagamento está fortemente associada ao valor percebido pelos consumidores. Normalmente porque o cliente pode sentir que está fazendo um bom negócio. Isso se torna um diferencial que a empresa pode proporcionar ao cliente.

A Figura 3 apresenta a percepção dos respondentes em relação aos fatores determinantes da compra. Em relação a esses fatores, $70 \%$ dos consumidores afirmam fazer pesquisa de mercado antes de comprar acabamentos e $28 \%$ pesquisam parcialmente. Com isso, percebe-se que a amostra do estudo é composta por consumidores exigentes e que realmente pesquisam e analisam várias opções antes de decidir realizar a compra. Possivelmente com o intuito de obter maior segurança em relação a sua decisão. Esse resultado reforça que o processo de decisão de compra é mais lento para os produtos de acabamentos, posto que exige mais tempo para análise e avaliação por parte do consumidor, o que retrata a compra de alto envolvimento (Solomon, 2016; Hawkins\&Mothersbaugh(2019).

\section{Figura 3: Fatores determinantes de compra}

\begin{tabular}{|c|c|c|c|c|c|c|}
\hline \multirow[t]{3}{*}{$\begin{array}{r}45,00 \% \\
40,00 \% \\
35,00 \% \\
30,00 \% \\
25,00 \% \\
20,00 \% \\
15,00 \% \\
10,00 \% \\
5,00 \% \\
0,00 \%\end{array}$} & \begin{tabular}{ll}
\multicolumn{2}{c}{$40 \%$} \\
$30 \%$ \\
\end{tabular} & $10 \%$ & $26 \%$ & $42^{\circ}$ & 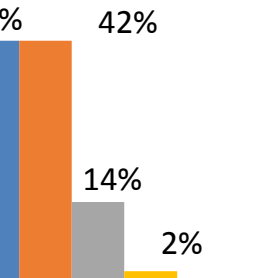 & $36 \% \quad 42 \%$ \\
\hline & $\begin{array}{l}\text { Sempre faço uma } \\
\text { pesquisa de mercado } \\
\text { antes de comprar } \\
\text { acabamentos }\end{array}$ & $\begin{array}{r}\text { Para rea } \\
\text { compra, o } \\
\text { necessi } \\
\text { entregues } \\
\mathrm{d}\end{array}$ & $\begin{array}{l}\text { lizar uma } \\
\text { s produtos } \\
\text { tam ser } \\
\text { no mesmo } \\
\text { ia }\end{array}$ & $\begin{array}{r}0 \\
\text { esser } \\
n\end{array}$ & $\begin{array}{l}\text { atendimento é } \\
\text { ncial na decisão da } \\
\text { minha compra }\end{array}$ & $\begin{array}{c}\text { Eu considero } \\
\text { importante um } \\
\text { projetista a disposição } \\
\text { para melhor visualizar o } \\
\text { meu projeto }\end{array}$ \\
\hline & ncordo Totalmente & Concordo & Parcialme & ente & Discordo & Discordo Totalmente \\
\hline
\end{tabular}

Fonte: dados da pesquisa

A pesquisa também relevou que $30 \%$ dos consumidores pesquisados não consideram importante os produtos serem entregues no mesmo dia e 
$40 \%$ se dizem parciais em relação a esse item. Possivelmente, esse resultado tenha se manifestado porque os clientes normalmente realizam as compras de acabamentos, quando sua construção está ainda na fundação. Até que a obra chegue ao momento da aplicação dos revestimentos em geral, demanda tempo. As empresas, por sua vez, aproveitam este tempo que o cliente não necessita do material, para se organizar com a compra na fábrica, para que o produto possa ser entregue na loja no prazo acertado. Já os $28 \%$ que assinalaram que concordam e concordam totalmente para a afirmativa referente à entrega no mesmo dia, possivelmente referem-se aos clientes que estão buscando itens de louças e metais, e que por isso precisam da entrega no ato da compra, para fazer a instalação imediata.

Em relação ao atendimento ser considerado essencial na decisão de compra, $42 \%$ dos clientes responderam que concordam totalmente e $42 \%$ que concordam, deixando claro que o atendimento foi considerado importante pelos pesquisados para que adquiram informações sobre os benefícios dos produtos que estão comprando. Com essas informações, é importante que as empresas tenham profissionais capacitados para melhor atender e entender o que o cliente deseja para que ele fique satisfeito.

Sobre a importância de ter um projetista para possibilitar a visualização dos produtos escolhidos pelo consumidor, $52 \%$ concordaram que este é um atributo importante, mostrando que muitos clientes gostam que o projetista apresente o projeto para que ele visualize melhor a proposta de vendas do produto. $42 \%$ marcaram parcialmente, pois dependendo da proporção da compra, o cliente já possui um arquiteto, não sendo totalmente necessária a utilização do projetista. Levando em conta este dado, é fundamental que as empresas considerem a oferta de um projetista qualificado para criar projetos compatíveis com as necessidades dos clientes, possibilitando que os mesmos os visualizem e sejam estimulados a adquirir aqueles produtos para sua construção.

\section{Satisfação dos Clientes}


O questionário respondido pelos consumidores também contemplou a avaliação de diversos indicadores, para os quais os respondentes assinalaram em uma escala de cinco pontos, o seu grau de satisfação em relação à cada item. A Tabela 1 apresenta as médias dos indicadores em ordem decrescente.

\section{Tabela 1: Indicadores de satisfação dos clientes}

\begin{tabular}{|l|r|}
\hline \multicolumn{1}{|c|}{ INDICADORES } & MÉDIA \\
\hline Estacionamento & 4,88 \\
\hline Localização da Loja & 4,72 \\
\hline Número de marcas oferecidas & 4,62 \\
\hline Atendimento pelo telefone & 4,60 \\
\hline Iluminação e Limpeza & 4,56 \\
\hline Informações passadas pelos vendedores & 4,52 \\
\hline Estrutura e Layout da Loja & 4,50 \\
\hline Qualidade dos Produtos & 4,48 \\
\hline Variedade de opções & 4,46 \\
\hline Horário de Atendimento & 4,44 \\
\hline Cafezinho oferecido & 4,38 \\
\hline Atendimento Pós-venda & 4,18 \\
\hline Formas de Pagamento & 4,02 \\
\hline Prazo de entrega & 3,92 \\
\hline Frequência de ofertas oferecidas & 3,84 \\
\hline Quantidade de produtos a pronta entrega & 3,80 \\
\hline Divulgação de produtos em redes sociais & 3,62 \\
\hline
\end{tabular}

Fonte: dados da pesquisa

Todos os indicadores avaliados se mostraram com média superior a 3, indicando uma percepção satisfatória por parte dos consumidores pesquisados. Os indicadores considerados mais satisfatórios foram 0 estacionamento e a localização da loja com médias 4,88 e 4,72, respectivamente. Com isso pode-se observar que a loja possui atrativos com relação ao ponto de venda que os clientes consideram importantes.

O número de marcas oferecidas também foi considerado satisfatório pelos consumidores, o que demonstra para as empresas o quão é importante a comercialização das marcas consagradas no mercado, e o acompanhamento dos lançamentos em feiras para disponibilizar na loja os 
produtos mais atuais do mercado, proporcionando ao cliente produtos que Ihes façam se sentir especiais em adquiri-los.

Os entrevistados também ficaram muito satisfeitos com o atendimento pelo telefone. Desta forma, é importante que as empresas entendam a importância dessa informação e capacitem os seus colaboradores para exercer esta atividade, ressaltando a importância de as informações serem comunicadas de forma cordial, clara e objetiva para que esse índice de satisfação se mantenha elevado.

Por outro lado, a média considerada menos satisfatória foi a divulgação de produtos através de redes sociais com média de 3,62. Para este índice, as empresas precisam atentar-se, pois trata-se de uma tendência de mercado. A sugestão é criar ações de interação com o consumidor via redes sociais, como sorteios de brindes e descontos na loja mediante compartilhamentos de conteúdos sobre a empresa, indicação de amigos e o desenvolvimento de concursos que despertem curiosidade e engajem os consumidores.

A quantidade de produtos a pronta entrega foi identificada como a segunda média mais baixa com 3,80. Em relação a esse item, é interessante agrupar os itens de maior saída e de maior importância desenvolvendo a curva ABC, para poder identificar os itens mais lucrativos para o negócio, fazendo a gestão de estoques de forma mais eficaz.

Outro indicador que obteve média mais baixa foi a frequência de ofertas com 3,84, o que demonstra ainda mais a importância de as empresas ampliarem as suas promoções e torna-las mais assíduas, para despertar a atenção dos clientes, especialmente por meio das redes sociais.

Por fim, outro indicador que também poderia ser melhorado é o prazo de entrega que ficou com média de 3,92. Esse resultado provavelmente ocorreu porque em algum momento um item comprado pelo cliente não foi entregue no prazo devido. É importante que as empresas desenvolvam uma melhor organização do tempo de entrega, priorizando os pedidos mais antigos, e também que o vendedor comunique um prazo maior de entrega 
para o cliente, pois às vezes a loja prevê um prazo baseando-se na data que o fornecedor indica, e pode acontecer desta data não ser cumprida, o que acaba atrasando também a entrega da loja para o cliente. Assim, o consumidor cria a expectativa de receber sua encomenda em determinada data e se frustra por a loja não cumprir com o prazo prometido.

Para resolver essa questão, sugere-se a utilização de planilhas de controle ou sistemas de informações gerenciais, que apresentassem data de emissão do pedido, itens do pedido que já estão na loja, itens que foram encomendados e data prevista de chegada e data da solicitação de entrega. Assim, os colaboradores teriam uma melhor organização, disporiam de informações mais precisas, o que viabilizaria dar retorno ao cliente durante o processo, reduzindo o número de reclamações.

\section{CONSIDERAÇÕES FINAIS}

Este estudo teve por objetivo analisar o comportamento do consumidor de produtos de acabamentos. Para isso, analisou-se o processo de decisão compra do consumidor e o seu nível de satisfação. Os objetivos foram atingidos por meio da aplicação de um survey com 50 consumidores de produtos de acabamentos.

A amostra pesquisada foi composta tanto por homens quanto por mulheres em sua maioria com idade acima dos 40 anos, casada e com alto poder de compra. Esse perfil é compatível com o público que se encontra no momento de construir ou reformar o seu lar e que busca produtos de qualidade para compor esse ambiente.

Com relação ao processo de decisão de compra, neste estudo, verificou-se que os consumidores, ao reconhecem uma necessidade, buscam informações de acabamentos tanto em lojas físicas quanto virtuais, optando por fazer pesquisa de mercado. Os consumidores pesquisados costumam avaliar as marcas, a qualidade e o preço juntamente com as condições de pagamentos, sendo que o atendimento recebido é um fator essencial na sua decisão de compra. 
Quanto à satisfação dos clientes em relação as suas compras, os indicadores avaliados mostraram-se favoráveis para a amostra pesquisada, com médias superiores a 3 em uma escala de cinco pontos. O indicador que mais se destacou foi o estacionamento, mostrando que os clientes pesquisados levam em consideração esse atributo oferecido, pois nem todas as empresas possuem estacionamento próprio e pode-se dizer que esse aspecto é um diferencial sendo considerado de grande importância. A respeito da estrutura, acontece o mesmo, pois o cliente vai até a loja com a expectativa de encontrar o que há de mais novo no mercado, produtos de qualidade aliado ao bom atendimento. Em virtude disso, as empresas necessitam estar sempre em busca de produtos diferenciados e exclusivos para melhor satisfazer seus clientes. Já os itens com índices mais baixos de satisfação foram as divulgações de produtos e a frequência de ofertas. Para estes, sugere-se a contratação de profissionais especializados para gerenciar as divulgações e fazer um acompanhamento nas redes sociais.

Esta pesquisa teve como fator limitador o fato de considerar uma amostra de 50 consumidores abordados no ponto de venda de apenas uma loja de produtos de acabamentos, o que gerou resultados baseados na percepção desta parcela estudada. Além disso, o estudo foi conduzido por meio de um survey, o que limita os resultados aos indicadores considerados no instrumento de pesquisa.

Diante disso, sugere-se que estudos futuros ampliem o escopo desta pesquisa, considerando uma amostra mais abrangente com consumidores em outros contextos. Com o intuito de acompanhar o nível de satisfação dos consumidores, recomenda-se a repetição da pesquisa com periodicidade anual. Também se recomenda a realização de um estudo na área de Gestão de Estoques com apoio da Curva ABC juntamente com um mapeamento de processos com ênfase nos prazos de entrega, para que as empresas obtenham índices de satisfação mais altos neste quesito.

A realização deste estudo proporcionou uma análise do comportamento do consumidor de produtos de acabamentos, englobando 
o processo de decisão de compra e a satisfação, oferecendo subsídios para tomada de decisões das empresas do ramo com vistas ao alcance de vantagens competitivas no mercado.

\section{REFERÊNCIAS}

Basso, K. \&Espartel, L. B. (2015) O uso de traços de personalidade para a diferenciação de consumidores em níveis de lealdade distintos. Contextus Revista Contemporânea de Economia e Gestão, 13, 1.

Belk, R. W.,Bahn, K. D., \& Mayer, R. N.

DevelopmentalRecognitionofConsumptionSymbolism. Journal of Consumer Research, 9, 1, 4-17.

Belk, R., Ger, G., \&Askegaard, S. (2003) The fire of Desire: a multisidedinquiry into consumer passion. Journal of Consumer Research, 30, December, 326351.

Brandão, E. D. (2005) Marketing descomplicado. Brasília: SENAC-DF.

Cobra, M. (2009)Administração de marketing no Brasil. 3. ed. Rio de Janeiro: Elsevier.

Brei, V. A. (2007) Da necessidade ao desejo de consumo: uma análise da ação do marketing sobre a água potável. Tese de doutorado, Universidade Federal do Rio Grande do Sul, Porto Alegre, RS, Brasil.

Crocco, L., Thelles, R., Gioia, R. M. (Coord.), Rocha, T., \&Strehlau, V. I. (2013) Fundamentos de marketing: conceitos básicos. 3ed. São Paulo: Saraiva.

Czinkota, M. (2001) Marketing: as melhores práticas. Porto Alegre: Bookman.

Ełzel, M. J., Walker, B. J., \& Stanton, W. J. (2001) Marketing. São Paulo: Makron Books.

Ferreira Junior, A. B., \&Centa, S. A. (2014) Supervarejo: uma abordagem prática sobre os mercados de consumo. Curitiba: Intersaberes. 
Gasper, D. (1996), 'Needs and basic needs.A clarification of meanings, levels and different streams of work'.Working Paper Series, n. 210. The Hague, The Netherlands: Institute of Social Studies.

Hawkins, D. I.,\&Mothersbaugh, D. L. (2019) Comportamento do Consumidor: construindo a estratégia de marketing. 13. Ed. Rio de Janeiro: Elsevier.

Holt, D. B. (1995) How Consumers Consume: a typology of consumption practices.Journal of Consumer Research, 22, 1, p. 1-16.

Ingenbleek, P. T. M.,Frambach, R. T, \&Verhallen, T. M. M. (2010) The Role of Value-Informed Pricing in Market-Oriented Product Innovation Management. Journal of Product Innovation Management, 27, 1032-1046.

McCracken, G. (1986) Culture and consumption: A theoretical account of the structureand movement of the cultural meaning of consumer goods. JournalofConsumerResearch, 13, 1, 71-84.

Malhotra, N. K. (2001) Pesquisa de marketing: uma orientação aplicada. 3. ed.Porto Alegre: Bookman.

Mascarenhas, S. A.(2012) Metodologia Científica. São Paulo: Pearson Education do Brasil.

Merskin, D. (2007) Truly Toffee and Raisin Hell: A Textual Analysis of Lipstick Names. Journal Sex Roles, 56, 9-10, 591-600.

Nickles, W. G., \& Wood, M. B. (1999) Marketing: relacionamentos, qualidade, valor. Rio de Janeiro: LTC.

Paladino, A. (2008) Analyzing the Effects of Market and Resource Orientations on Innovative Outcomes in Times of Turbulence. JournalofProductInnovation Management, 25, 577-592.

Paixão, M. V. (2012) A influência do consumidor nas decisões de marketing. Curitiba: InterSaberes.

Pinheiro, R. M., Castro, G. C., Silva, H. H., \& Nunes, J. M. G. (2006) Comportamento do consumidor e pesquisa de mercado. 3. ed. Rio de Janeiro: Editora FGV.

Reichelt, V. P. (2013) Fundamentos de Marketing.Curitiba: Intersaberes. 
Reid, S. E.,\&Brentani, U. (2010) Market Vision and Market Visioning Competence: Impact on Early Performance for Radically New, High-Tech Products. Journal of Product Innovation Management, 27, 500-518.

Ribeiro, L. (org). (2015) Marketing social e comportamentodoconsumidor. São Paulo: Pearson Education do Brasil.

Solomon, M. R. (2016) O comportamento do consumidor: comprando, possuindo e sendo. 11. ed. Porto Alegre: Bookman.

Strehl, E. G., Mello Moyano, C. A. \&Angnes, D. L. (2019)Atributos qualitativos e fatores de satisfação com o transporte público urbano por ônibus.CONTEXTUS - RevistaContemporânea de Economia e Gestão, 17, 1, 98-126.

Wu, J. (2013) Marketing capabilities, institutional development, and the performance of emerging market firms: a multinational study. International Journal of Research in Marketing, 30, 36-45.

Zeithaml, V. A., Bitner, M. J., \&Gremler, D. D. (2014)Marketing de serviços: a empresa com foco no cliente. 6. ed. Porto Alegre: McGraw Hill Education. 